\title{
Remark on the Laplacian-energy-like and Laplacian incidence energy invariants of graphs
}

\section{I. Ž. Milovanović, E. I. Milovanović, M. R. Popović and R. M. Stanković}

\section{ABSTRACT.}

Let $G$ be an undirected connected graph with $n$ vertices and $m$ edges, $n \geq 3$, and let $\mu_{1} \geq \mu_{2} \geq \cdots \geq \mu_{n-1}>\mu_{n}=0$ and $\rho_{1} \geq \rho_{2} \geq \cdots \geq$ $\rho_{n-1}>\rho_{n}=0$ be Laplacian and normalized Laplacian eigenvalues of $G$, respectively. The Laplacian-energy-like (LEL) invariant of graph $G$ is defined as $\operatorname{LEL}(\mathrm{G})=\sum_{\mathrm{i}=1}^{\mathrm{n}-1} \sqrt{\mu_{\mathrm{i}}}$. The Laplacian incidence energy of graph is defined as $\operatorname{LIE}(\mathrm{G})=\sum_{\mathrm{i}=1}^{\mathrm{n}-1} \sqrt{\rho_{\mathrm{i}}}$. In this paper, we consider lower bounds of graph invariants $\operatorname{LEL}(\mathrm{G})$ and $\operatorname{LIE}(\mathrm{G})$ in terms of some graph parameters, that refine some known results.

Acknowledgements. This work was supported by the Serbian Ministry of Education and Science, Project No TR32012 and TR32009.

\section{REFERENCES}

[1] Andova, V., Bogoev, S., Dimitrov, D., Pilipczuk, M. and Škrekovski, R., On the Zagreb index inequality of graphs with prescribed vertex degrees, Discrete Appl. Math., 159 (2011), 852-858

[2] Biggs, N. L., Algebraic graph theory, Cambridge: Cambridge Univ. Press, 1974

[3] Cavers, M., Fallat, S. and Kirkland, S., On the normalized Laplacian energy and general Randić index $R_{-1}$ of graphs, Linear Algebra Appl., 433 (2010), 172-190

[4] Chen, S. and Liu, W., Extremal Zagreb indices of graphs with a given number of cut edges, Graphs Combin., 30 (2014), 109-118

[5] Chung, F. R. K., Spectral graph theory, Providence: Am. Math. Soc., 1997

[6] Das, K. Ch., Gutman, I. and Çevik, A. S., On the Laplacian-energy-like invariant, Lin. Algebra Appl., 442 (2014), 58-68

[7] Edwards, C. S., The largest vertex degree sum for a triangle in a graph, Bull. London Math. Soc., 9 (1997), 203-208

[8] Li, X. and Yang, Y., Sharp bounds for the general Randić index, MATCH Commun. Math. Comput. Chem., 51 (2001), 155-166

[9] Liu, J. and Liu, B., A Laplacian-energy-like invariant, MATCH Commun. Math. Comput. Chem., 59 (2008), 392-419

[10] Shi, L., Bounds on Randić indices, Discrete Math., 30 (2009), No. 16, 5238-5241

[11] Shi, L.and Wang, H., The Laplacian incidence energy of graphs, Lin. Algebra Appl., 439 (2013), 4056-4062

[12] Shisha, O. and Mond, B., Bounds on differences of means, Inequalities I, New York - London, 1967, 293-308

[13] Zumstein, P., Comparison of spectral methods through the adjacency matrix and the Laplacian of a graph, Th. Diploma, ETH Zürich, 2005

FACULTY OF ELECTRONIC ENGINEERING

A. MedvedeVA 14, P.O.Box 73, 18000 Niš, SERBiA

E-mail address: igor@elfak.ni.ac.rs

Business SCHOOL OF APplied STUdies

18420 BLACE, SERBIA

E-mail address: r.stankovic@vpskp.edu.rs 